\title{
The development of hemochromatosis after treatment for celiac sprue
}

\author{
MANG MA MD, EDMOND A RYAN MD, VINCENT G BAIN MD
}

M MA, EA RYAN, VG BAIN. The development of hemochromatosis after treatment for celiac sprue. Can J Gastroenterol 1994;8(6):358-361. Celiac sprue is a chronic disease characterized by maldigestion and malabsorption. Whereas many diseases have been reported in association with celiac sprue, hemochromatosis has not. A 62-year-old man with celiac sprue and a history of iron deficiency and osteopenic bone disease who developed hemochromatosis is reported. Liver biopsy showed portal tract fibrosis, early nodule formation and increased hepatic iron storage. The patient developed hemochromatosis with hepatic injury two years after his transferrin saturation became elevated and 10 years after he had been placed on gluten-free diet. Lifelong iron accumulation was prevented by chronic malabsorption of iron but hemochromatosis became manifest when his celiac sprue was treated.

Key Words: Celiac, Cirrhosis, Gluten-free diet, Hemochromatosis, Malabsorption

\section{Installation d'une hémochromatose après traitement pour la sprue}

RÉSUMÉ : La sprue est une maladie chronique caractérisée par un défaut de digestion et d'absorption. Plusieurs affections ont été rapportées en association avec la sprue; l'hémochromatose ne l'avait pas encore été. Un homme de 62 ans atteint de sprue et ayant des antécédents de carence en fer et d'ostéopénie et qui a développé une hémochromatose, est présenté ici. La biopsie hépatique a révélé une fibrose de la voie portale, la formation précoce de nodules et l'augmentation des réserves ferriques hépatiques. Le patient a développé une hémochromatose avec lésions hépatiques deux ans après l'élévation de son taux de saturation de la transferrine et 10 ans après l'instauration chez lui d'un régime sans gluten. L'accumulation ferrique pour la durée de la vie a été prévenue par la malabsorption chronique du fer, mais l'hémochromatose est devenue manifeste lorsque la sprue a été traitée.

Department of Medicine, University of Alberta, Edmonton, Alberta

Correspondence: Dr VG Bain, 2E3.27 WCM, University of Alberta, Edmonton, Alberta

T6G 2R7. Telephone (403) 492-7238, Fax (403) 492-3340

Received for publication February 14, 1994. Accepted April 21, 1994
O ELIAC SPRUE IS A CHRONIC DIS. ease characterized by absence of villi causing a flattened mucosal surface, and crypt hyperplasia of the small intestine. There is extensive lymphocyte and plasma cell infiltration of the lamina propria. These changes are caused by an immune reaction induced by the ingestion of gluten-containing foods. As a result of mucosal injury, digestive process and nutrient absorption are impaired (1).

The symptoms of celiac sprue depend on the length of small intestine that has been damaged after gluten ingestion. Patients with extensive small bowel disease have fatigue, weight loss, steatorrhea and other symptoms of malabsorption. Patients with proximal small intestine involvement can present with iron deficiency, folate deficiency or osteopenic bone disease. These deficiencies can be corrected after treatment with gluten-free diet.

Many diseases have been reported in association with celiac sprue. These include dermatitis herpetiformis, diabetes mellitus, thyroid disease, immunoglobulin A deficiency and nephropathy, ulcerative colitis, sclerosing cholangitis, primary biliary cirrhosis and lymphoma (2,3). An abnormal immune response has been implicated as 
the underlying cause in all these diseases. Hemochromatosis has not been reported in association with cẹliac disease. We report the case of a 62 -yearold male who developed hemochromatosis after being treated for celiac sprue with a gluten-free diet. This case also provides insight into the time required for hepatic injury secondary to iron overloading.

\section{CASE PRESENTATION}

A 62-year-old male with a long history of osteomalacia secondary to celiac sprue was investigated because of persistently abnormal liver enzymes and a raised serum ferritin. He had chronic back pain and a borderline elevated aspartate aminotransferase (AST) for more than 20 years. At age 49 he was admitted into the hospital because of severe back pain. At that time, he complained of loose bowel movements in the past year. Radiological investigation showed vertebral collapse of T10, $\mathrm{T} 11$ and T12. There was significant osteopenia involving his spine. Blood work showed (normal range in brackets): calcium, $9 \mathrm{mg} / \mathrm{dL}$ ( 8 to 10 ); vitamin $D_{3}, 24.6 \mathrm{mg} / \mathrm{mL}$; serum carotene, $12 \mu \mathrm{g} / \mathrm{dL}$ ( 50 to 250 ); folic acid, $1.2 \mu \mathrm{g} /$ $\mathrm{mL}$ (1.7 to 8.6); vitamin $\mathrm{B}_{12}, 259 \mathrm{pg} /$ $\mathrm{mL}$ ( 140 to 520 ); iron, $44 \mu \mathrm{g} / \mathrm{dL}$ ( 65 to $145)$; total iron binding capacity, 288 $\mu \mathrm{g} / \mathrm{dL}$ (250 to 400); transferrin saturation, $15 \%$ (20 to $45 \%$ ); AST, $223 \mathrm{IU} / \mathrm{L}$ (10 to 55); lactate dehydrogenase (LDH), 274 IU/L (100 to 220); 5' nucleotidase, 377 IU/L (5 to 15 ) and alkaline phosphatase (AKP), $744 \mathrm{IU} / \mathrm{L}$ (40 to 110). Stool weight was $342 \mathrm{~g} /$ day and fecal fat was $14.9 \mathrm{~g} /$ day (normal 0 to 5).

Small bowel biopsy showed complete loss of villi and increased cellularity of the lamina propria (Figure 1). Liver biopsy showed no evidence of an inflammatory infiltrate or excessive iron storage (Figure 2). Endoscopic retrograde cholangiopancreatography was normal. However, it was believed the patient had passed a gallstone.

The patient was placed on a glutenfree diet, with calcium and vitamin D supplements. He was discharged with the diagnosis of celiac sprue with osteomalacia. His liver enzymes normalized on the gluten-free diet.

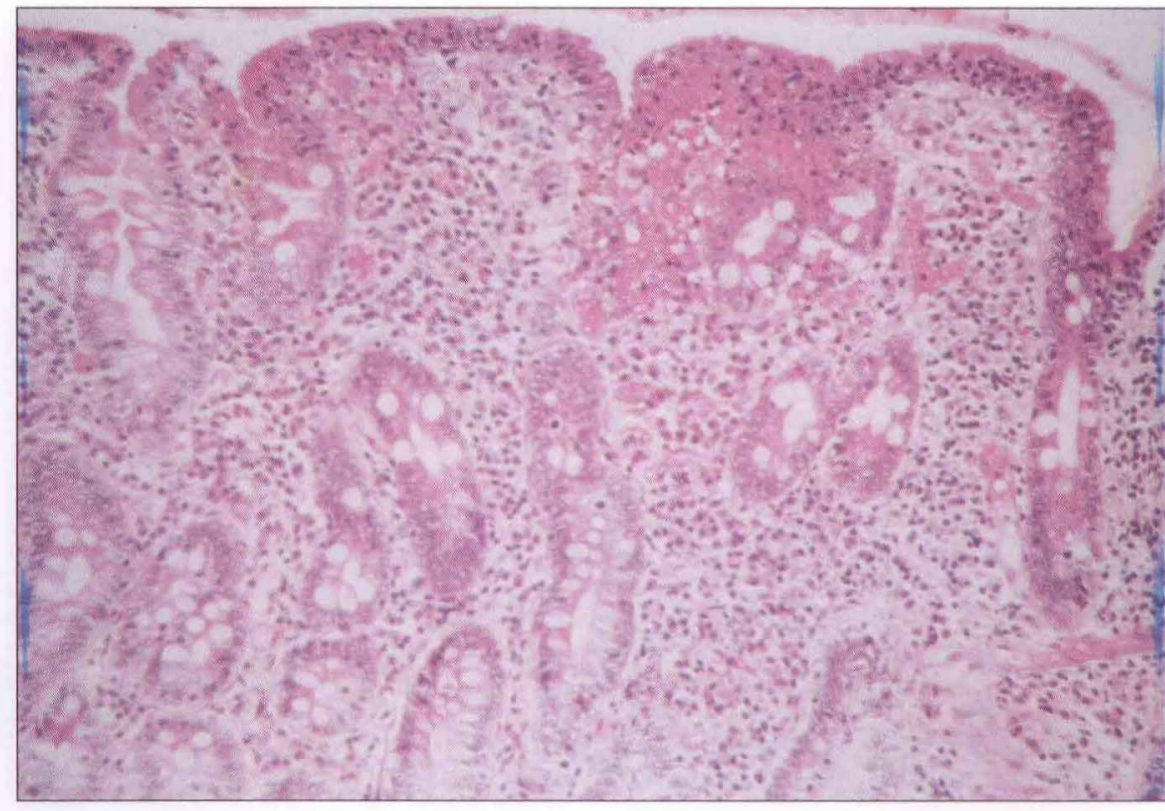

Figure 1) Small bowel biopsy showed complete loss of villi and increased cellularity at the lamina propria

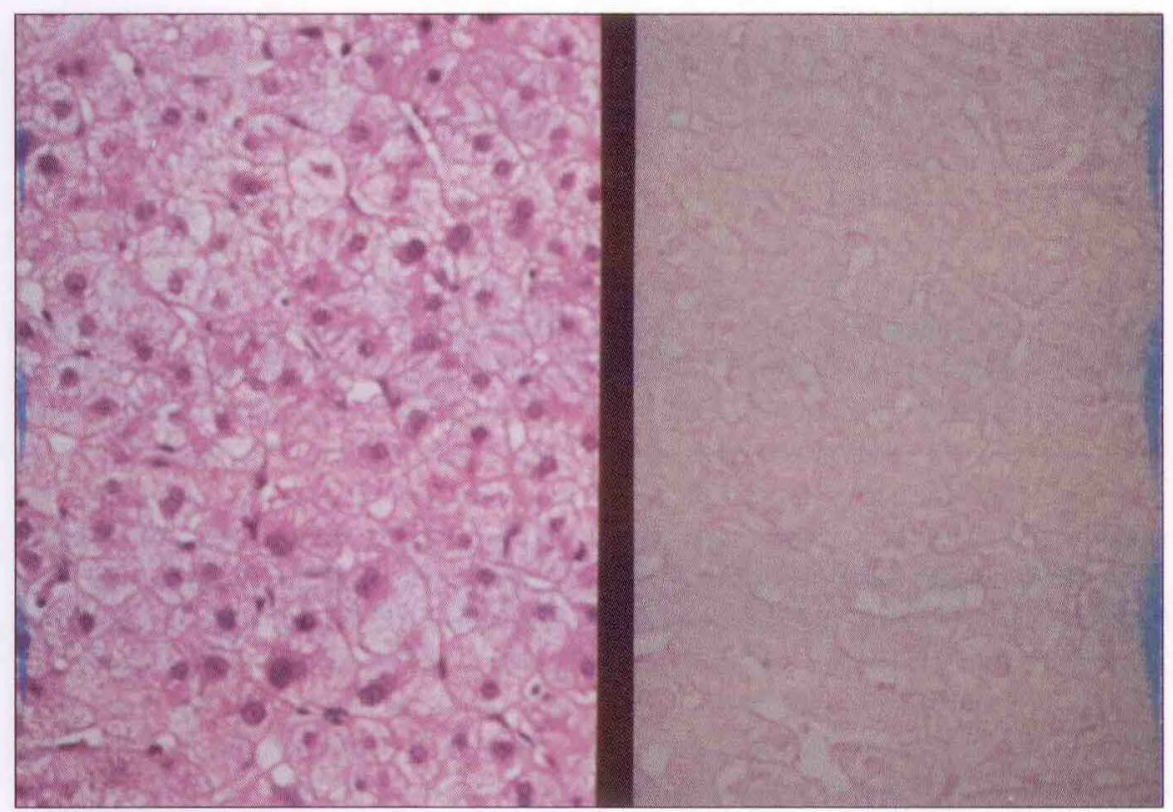

Figure 2) First liver biopsy of patient at age 49 showed no evidence of hepatitis (left) or excessive iron storage by iron stain (right)

Over the next eight years he was well except for bone pain secondary to osteopenic bone disease. Two years ago at age 60 he was discovered to have kyphosis and his height had decreased by $3 \mathrm{~cm}$. AST was $84 \mathrm{IU} / \mathrm{L}$, AKP $362 \mathrm{IU} /$ $\mathrm{L}$, serum iron $33 \mu \mathrm{mol} / \mathrm{L}$, transferrin saturation $66 \%$ and ferritin $456 \mu \mathrm{g} / \mathrm{L}$ (normal 25 to 465). Fluoride and vitamin D supplements were added; subsequently the fluoride was replaced by etidronate. Two years later, his liver enzymes continued to be abnormal.

Past medical history included mumps with the complication of testicular atrophy at age 17 . The patient was a retired grocery store owner. He was a nonsmoker. He consumed up to half a bottle of rum weekly. He was divorced and had no children. His medication included calcium supplement, etidronate, depotestosterone in- 


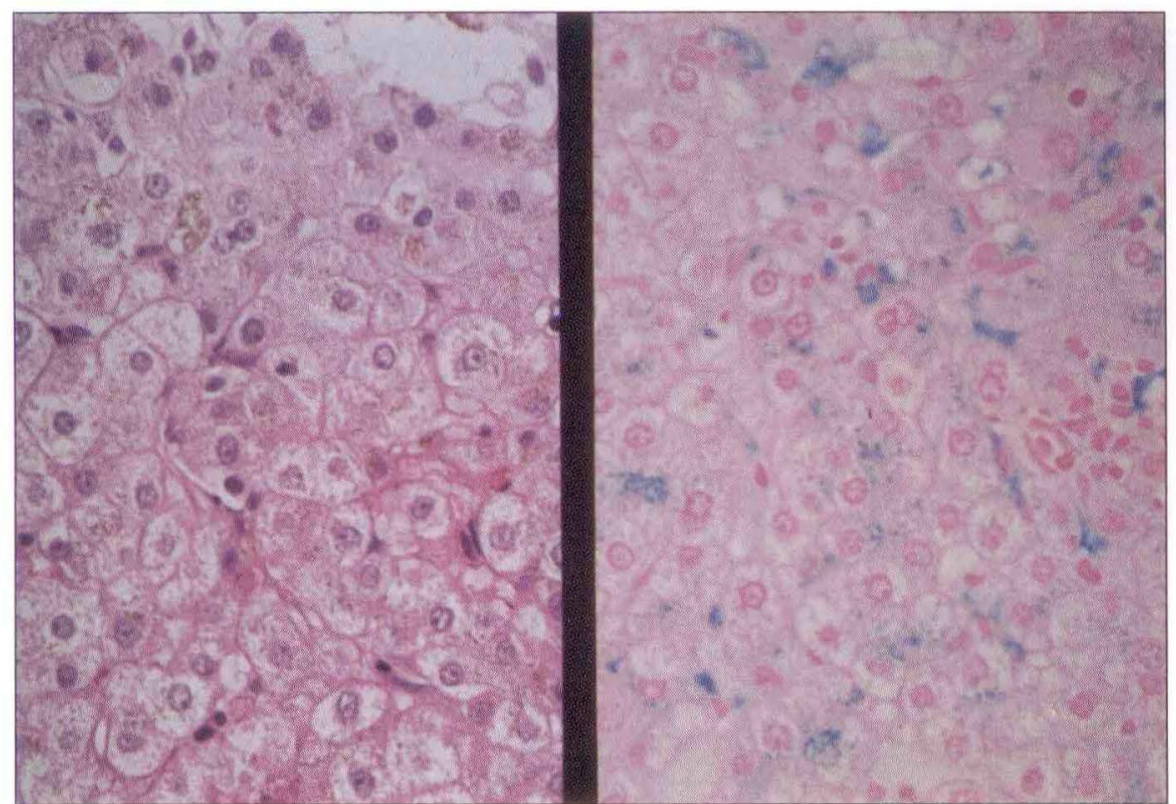

Figure 3) Second liver biopsy of patient at age 61 showed iron pigments in both hepatocytes and Kupffer cells. Left Hematoxylin and eosin stain; Right Iron stain

jection and multivitamins without iron. There was a family history of gastric and breast cancer, ischemic heart disease, and his mother had celiac disease. There was no history of hemochromatosis or other liver disease.

Physical examination showed kyphosis and hyperpigmented skin without jaundice. His chest was clear. There was no evidence of heart failure. His abdomen was soft, nontender and there was no evidence of hepatosplenomegaly. Neurological examination was normal. He had no inflamed joints. AST was $118 \mathrm{IU} / \mathrm{L}, \mathrm{LDH} 742 \mathrm{IU} / \mathrm{L}$, AKP 287 $\mathrm{IU} / \mathrm{L}$, bilirubin $16 \mu \mathrm{mol} / \mathrm{L}$, serum iron $32 \mu \mathrm{mol} / \mathrm{L}$, transferrin saturation $70 \%$ and serum ferritin over $500 \mu \mathrm{g} / \mathrm{L}$. Serology for hepatitis B and C was negative. A liver biopsy showed portal tract fibrosis, early incomplete nodule formation and steatosis. Iron stain showed widespread iron pigment in Kupffer cells and in hepatocytes (Figure 3). The hepatic iron level was elevated to 42.9 $\mu \mathrm{mol} / \mathrm{g}$ of dry tissue. Human leukocyte antigen (HLA) phenotype was A11, A31, B14, Bw48, C28. Weekly phlebotomy was initiated.

\section{DISCUSSION}

This 62-year-old male had biopsydocumented celiac sprue with a classic flat mucosal lesion. As a result of small bowel mucosal injury, he developed malabsorption leading to steatorrhea and osteomalacia. However, his symptoms were insidious in onset and his bone disease was advanced before celiac sprue was diagnosed. A liver biopsy obtained at the time his celiac sprue was diagnosed was normal, and specifically there was no evidence of iron accumulation. When our patient was placed on a gluten-free diet, his liver enzymes improved. As previously reported (4), patients with celiac sprue often have abnormally elevated liver enzymes (AST, alanine aminotransferase, AKP) and nonspecific histological changes in the liver, including expanded portal triads, mononuclear infiltration, steatosis and focal hepatocyte necrosis, but these tend to improve with gluten exclusion.

Eleven years after institution of a gluten-free diet, the patient was diagnosed with hemochromatosis after being investigated for persistently abnormal liver enzymes and elevated transferrin saturation. After he had been on gluten-free diet for nine years, his serum iron had risen from 7 to 33 $\mu \mathrm{mol} / \mathrm{L}$ and his transferrin saturation had risen from 15 to $66 \%$ with a normal ferritin level. Two years later, his transferrin saturation was $70 \%$ and his ferritin was over $500 \mu \mathrm{g} / \mathrm{L}$. Liver biopsy at this time showed bridging fibrosis with incomplete nodule formation and excessive parenchymal iron storage compatible with hemochromatosis (Figure 3).

We believe this patient has genetic hemochromatosis which was masked by iron malabsorption secondary to untreated celiac sprue. After his celiac sprue was treated, increased iron absorption helped to replenish his tissue and hepatic iron. Thereafter, he continued to absorb and accumulate iron inappropriately as evidenced by an elevated transferrin saturation and serum ferritin. The predominant localization of iron within hepatocytes is typical of genetic hemochromatosis, whereas in secondary iron overload (as in excessive alcohol consumption or hemolytic anemia), iron is found in Kupffer cells. With no other explanation such as hepatitis $\mathrm{B}$ or $\mathrm{C}$ or excess alcohol intake, we attribute the hepatic changes demonstrated on the second liver biopsy to the toxic effects of excessive iron deposition.

The hepatic iron index (hepatic iron in $\mu \mathrm{mol} / \mathrm{g}$ divided by age in years) is a reliable indicator for hemochromatosis because an age-related rise in hepatic iron is seen only in hemochromatosis. An index greater than 2 is useful to distinguish hemochromatosis from other causes of iron overload including alcoholic liver disease $(5,6)$. The hepatic iron index cannot be applied directly to this patient because he had malabsorption of iron before his celiac sprue was treated. Only in the past 10 years did the patient have the opportunity to accumulate iron. Thus, his corrected hepatic iron index is $4.3(42.9 \mu \mathrm{mol} / \mathrm{g} / 10$ years $)$. This index is compatible with avid and inappropriate iron absorption (7) in the presented patient during the decade following correction of malabsorption and is best explained by the coexistence of genetic hemochromatosis.

An alternate explanation would attribute this patient's liver disease to chronic autoimmune hepatitis which may occasionally accompany celiac sprue, and his excessive hepatic iron to his modest alcohol consumption. Al- 
though plausible, we consider this scenario less likely for the following reasons: the liver function tests improved dramatically at the time of gluten exclusion as described in celiac patients with nonspecific histological findings (4); chronic active hepatitis of autoimmune origin predominates in women and is generally an aggressive lesion yet our patient did not have such a clinical course; neither liver biopsy showed a significant inflammatory infiltrate to support a diagnosis of chronic active hepatitis; and the hepatic iron was predominantly parenchymal rather than within Kupffer cells as in excessive alcohol consumption. For these reasons we believe the diagnosis of genetic hemochromatosis is the most likely ex-

\section{REFERENCES}

1. Working Group of European Society of Pediatric Gastroenterology and Nutrition. Revised criteria for diagnosis of celiac disease. Arch Dis Child 1990;65:909-11.

2. Trier JS. Celiac sprue. N Engl J Med 1991;325:1709-19.

3. Cooke WT, Holmes GKT. Celiac Disease. New York: Churchill Livingstone, 1984.

4. Jacobsen MB, Fausa O, Elgjo K, Schrumpf E. Hepatic lesions in adult celiac disease. Scand J Gastroenterol 1990;25:656-62. planation for this patient's clinical course.

The genetic hemochromatosis allele resides at a locus close to HLA A and HLA B loci on chromosome 6 . There is a strong link between genetic hemochromatosis and HLA A3, A11, B7 and B14 (8). The patient has HLA A11 and B14, which are associated with hemochromatosis. In contrast, celiac sprue is associated with DQW2 which has strong links with DR3 and B8 (9). Thus, there is no reported direct link between celiac sprue and hemochromatosis.

Although the true prevalence for celiac sprue is probably higher, the prevalence rate has been reported to be between 1:1000 and 1:2000 (2). For

5. Bassett ML, Halliday JW, Powell LW. Value of hepatic iron measurement in early hemochromatosis and determination of the critical iron level associated with fibrosis. Hepatology 1986;6:24-9.

6. Tavill AS. Hemochromatosis: how much iron is too much? Hepatology 1986;6:142-5.

7. Lombard M, Bomford AB, Polson RJ, et al. Differential expression of transferrin receptor in duodenal mucosa in iron overload. Gastroenterology 1990;98:976-84.

8. Simon M, Yaouangq J, Fauchet R, hemochromatosis, the prevalence rate is 1:400 (10). The possibility of having both celiac sprue and hemochromatosis can therefore be estimated at between $1: 400,000$ and $1: 800,000$ if it is assumed that the two are unrelated (the prevalence rate of celiac sprue $X$ the prevalence rate of hemochromatosis). We believe the patient reported has both diseases because of chance occurrence. This case also provides the unique observation of avid iron absorption and rapid hepatic injury occurring within 11 years in genetic hemochromatosis. Iron overload and hepatic injury can occur rapidly in genetic hemochromatosis. It is essential to diagnose and treat hemochromatosis early.

et al. Genetics of hemochromatosis: HLA association and mode of inheritance. Ann N Y Acad Sci 1988;526:11-22.

9. Marsh MN. Gluten, major histocompatability complex, and the small intestine: a molecular and immunobiologic approach to the spectrum of gluten sensitivity ("celiac sprue"). Gastroenterology 1992;102:330-54.

10. Adams PC, Kertesz AE, Valberg LS. Clinical presentation of hemochromatosis: a changing scene. Am J Med 1991;90:445-9. 


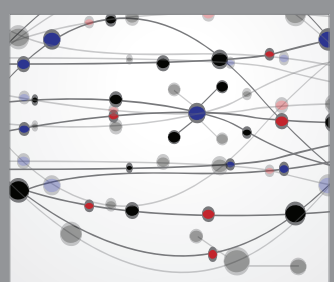

The Scientific World Journal
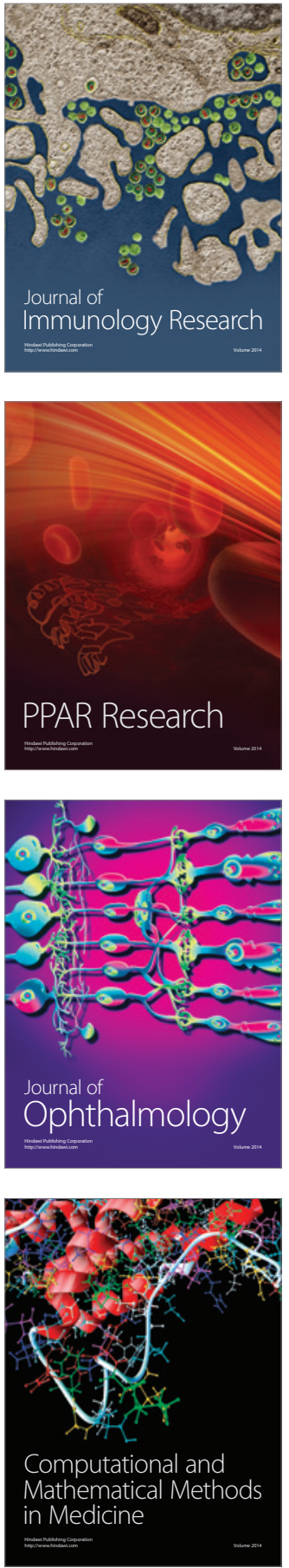

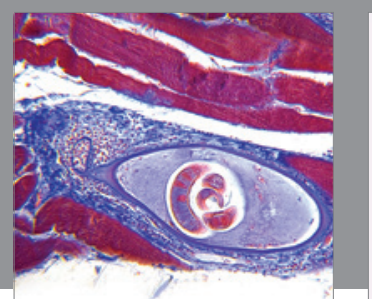

Gastroenterology Research and Practice

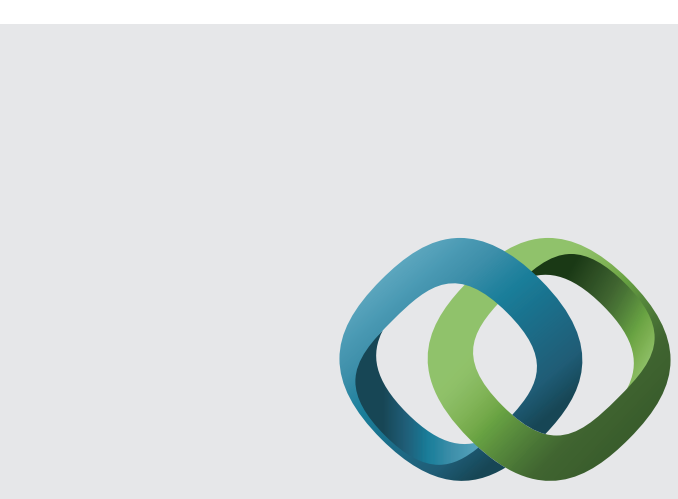

\section{Hindawi}

Submit your manuscripts at

http://www.hindawi.com
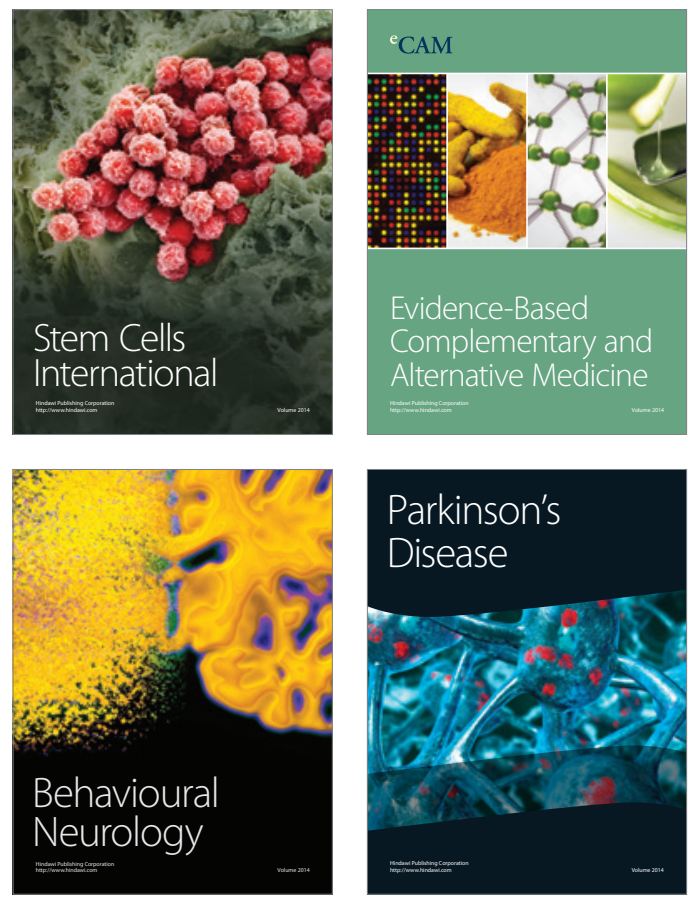
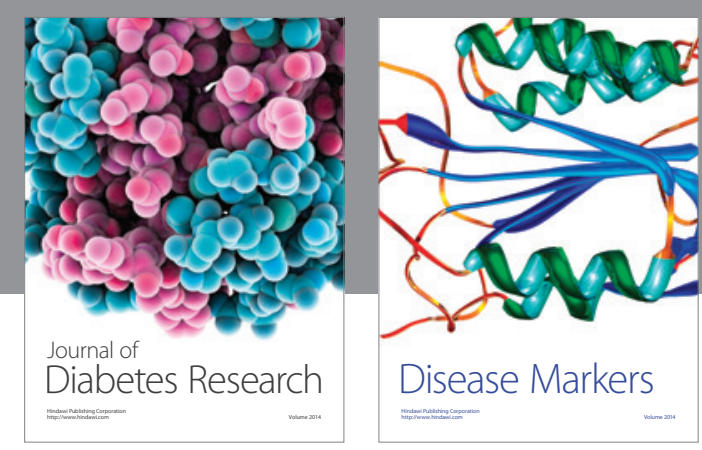

Disease Markers
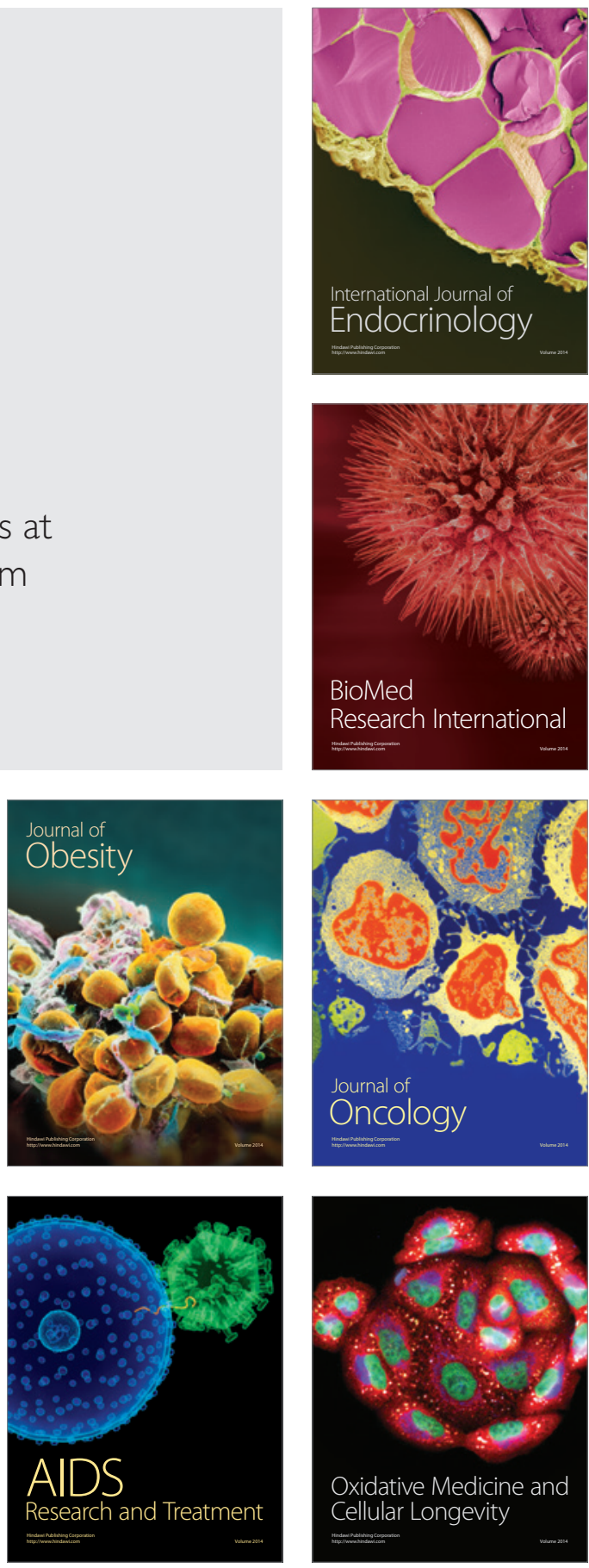